\title{
Peertechz
}

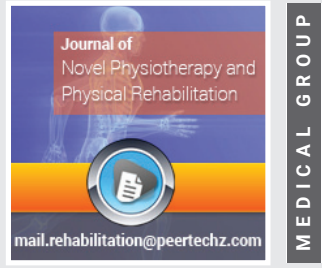

\section{Posterior approach to the Hip}

\section{Joint}

\author{
K Mohan lyer* \\ Senior Consultant, Orthopedic Surgeon, Bangalore, India
}

Received: 16 July, 2021

Accepted: 06 August, 2021

Published: 07 August, 2021

*Corresponding author: K Mohan Iyer, Senior Consultant, Orthopedic Surgeon, Bangalore, India, E-mail:kmiyer28@hotmail.com

https://www. peertechzpublications.com
The hip joint is one of the most surgically exposed joints in the body [1]. The posterior approach is known to have a slightly higher risk of dislocations [2], whilst the anterior [3] and lateral approaches [4] allow for preservation of the posterior soft tissue envelope. I had developed a modification of the Posterior Approach at a time when the regular Posterior Approach was plagued with the problem of dislocation. Hence this modification was devised after cadaveric tests confirming superiority by increasing its stability and thus prevent dislocation of the Hip joint. This is a posterior trochanter spliting approach to the Hip Joint by maintaining all the advantages of the Posterior Approach with excellent visualization of the Hip Joint. This was then used in patients with a fracture neck femur for insertion of an endoprosthesis.

The detailed Clinical Technique stepwise in 11 steps is as described below:

There were no dislocations nor instability noted in the followup of these patients. This approach was then described by Mark Conventry [5] in the year book of Orthopaedics, Terry Canale of Campbell's Operative Orthopaedics (1992) [6] till finally by my respected teacher Mr.F.H. Beddow in the Rheumatoid Arthritis Surgical Society (1990) [7]. Thereafter many people like James Shaw [8] did appreciate this approach and it was mentioned in books by John J Callaghan MD, Aaron G Rosenberg MD, Harry E Rubash in The Adult Hip (1998) [9] and Surgery of the Hip by Raymond Tonzo [10] and finally in Minimally Invasive Total Joint Arthroplasty (2004) [11] by William J Hozak, Martin Kirsmer, Michael Hogler, Peter M Bonutti, Franz Rachbauer, Jonathan L Scaffer, William J Donnelly. Above all Thomas Stahelin [12] of Zurich, Switzerland finally acknowledged the value of this approach. Deepa Iyer (2006) [13] and Robert H Cofield [14] of Mayo clinic (2005) in the USA did acknowledge this approach by carrying out their studies with reporting their results in the Acta Orthopaedica Belgica [15]. The main pupose of this modification was to avoid dislocation of the Hip Joint and yet retain all the advantages of the posterior approach Figures 1-14.
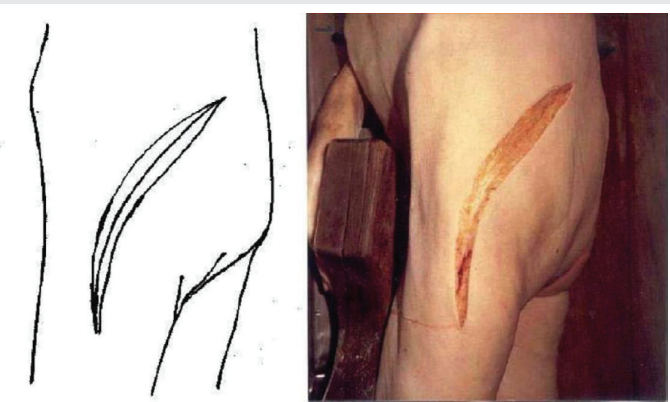

Figure 1: Skin Incision from the distal and lateral part of the trochanter to the posterior superior iliac spine with a gentle curve in the direction of the fibers of the gluteus maximus.
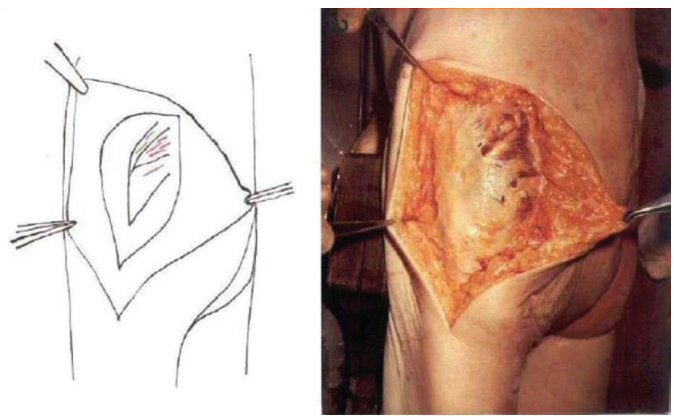

Figure 2: Incision through the gluteal fascia.

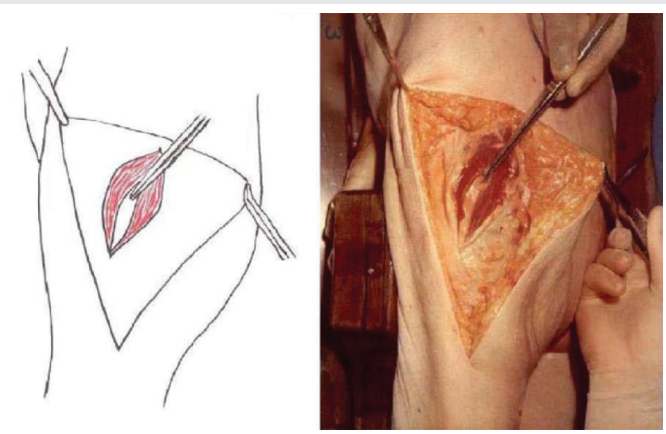

Figure 3: Incision vertically through the fibers of the gluteus maximus. 
In the end, my book The Hip Joint( $2^{\text {nd }}$ Edition) [16] by Jenny Stanford Publishing(Singapore) which contains 32 important chapters was released in June 2021.

The basic attempts at this have been numerous Modifications to the Posterior Approach with an aim of adding more stability by numerous soft tissue enhancement procedures to the Hip Joint posteriorly.

Comments by Sushnma PT, Hyderabad, India
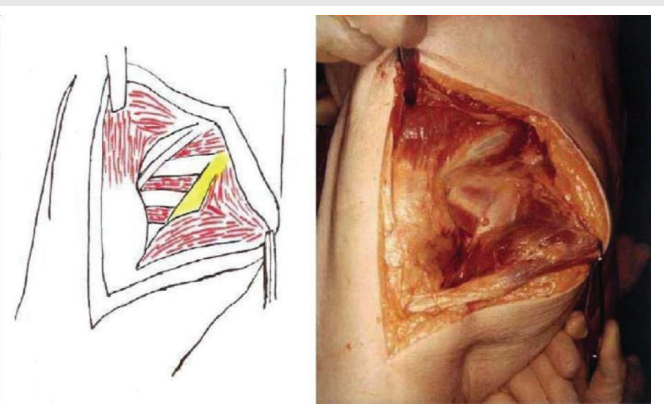

Figure 4: Exposure of the short lateral rotators.

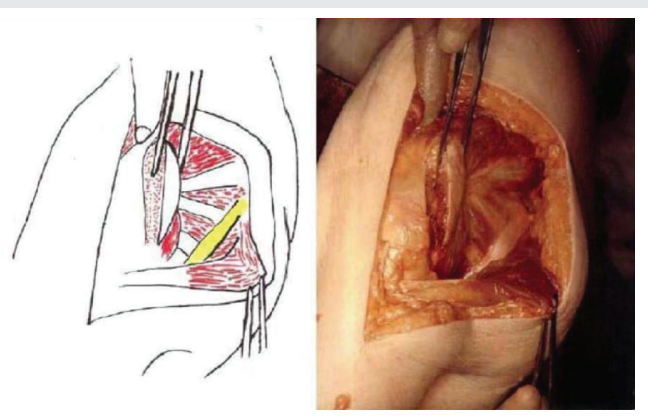

Figure 5: Posterior Tochanteric Osteotomy taking the insertion of the short lateral rotators with the sciatic nerve well away.
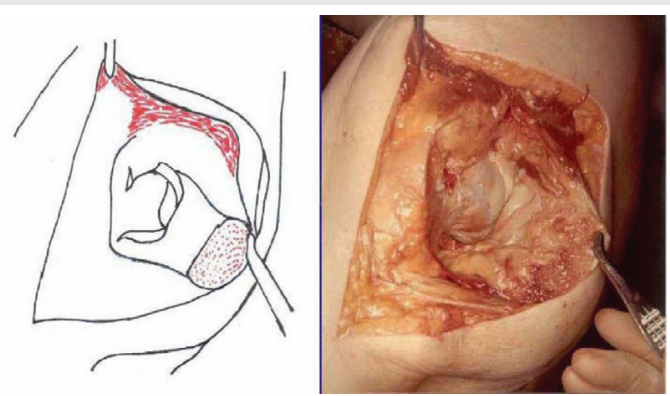

Figure 6: Exposure of the Hip Joint.
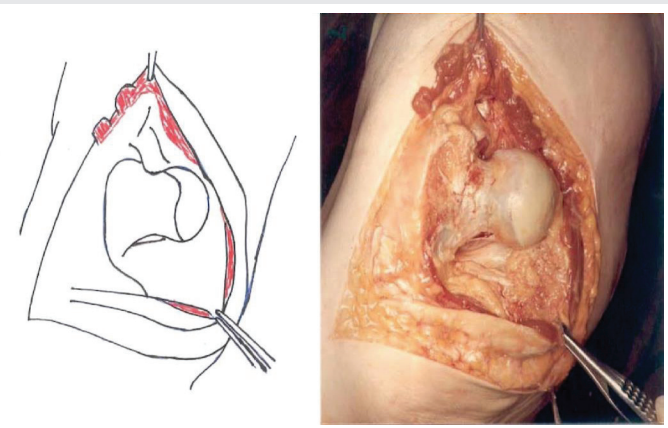

Figure 7: Dislocation of the Hip Joint.
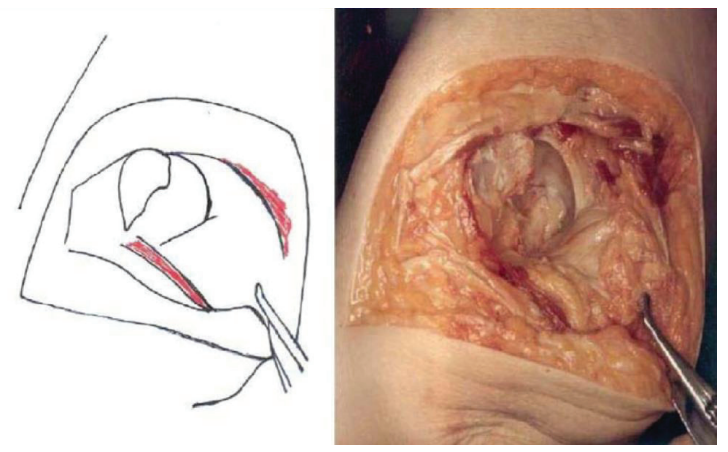

Figure 8: Resection of the head and neck of the femur.
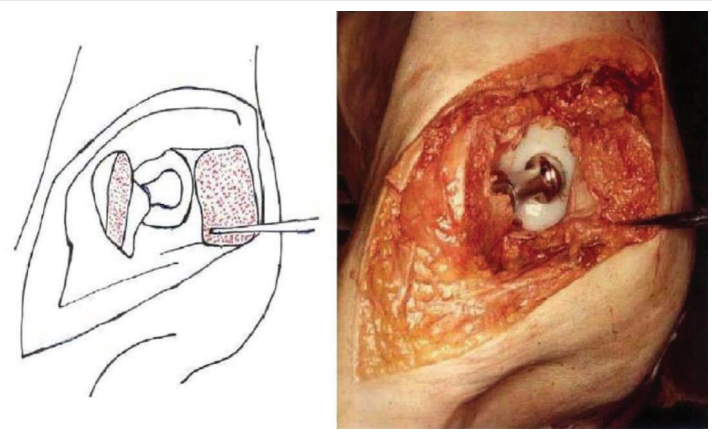

Figure 9: Insertion of the Total Hip Prosthesis.

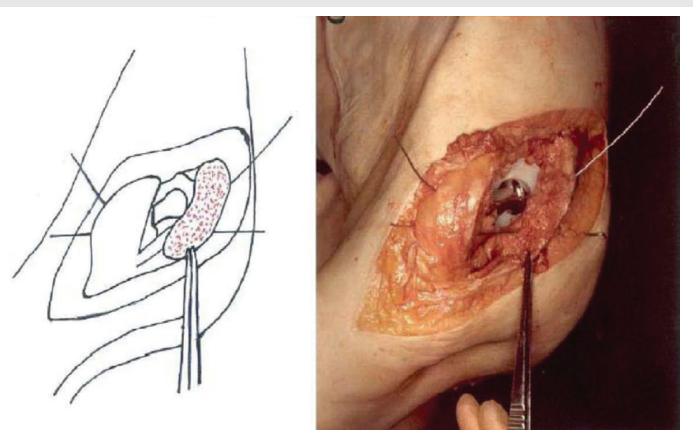

Figure 10: Wiring of the trochanteric fragment.
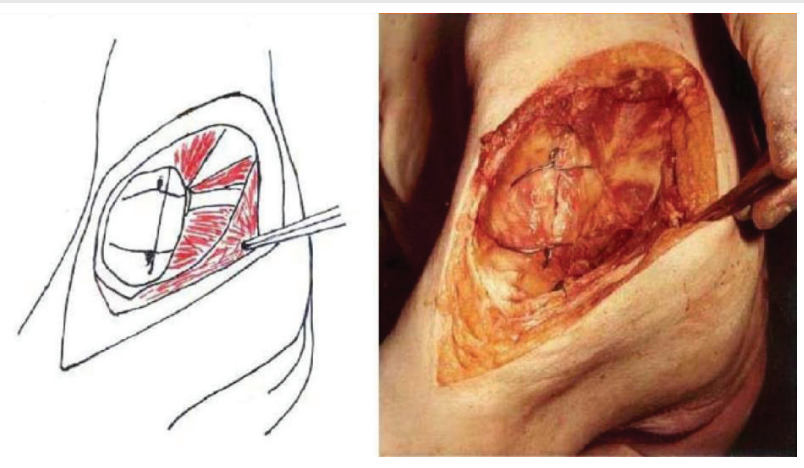

Figure 11: Reconstitution of the Hip Joint.

Modified posterior approach of hip is definitely a great option than posterior approach or any other approaches because this technique provides greater stability and reduce the chances of dislocation. Most importantly, there is No muscle or nerve damage. For instance, Lateral Rotators, Gluteus Medius are not cut, Sciatic nerve is saved, Abductor mechanism is intact. 


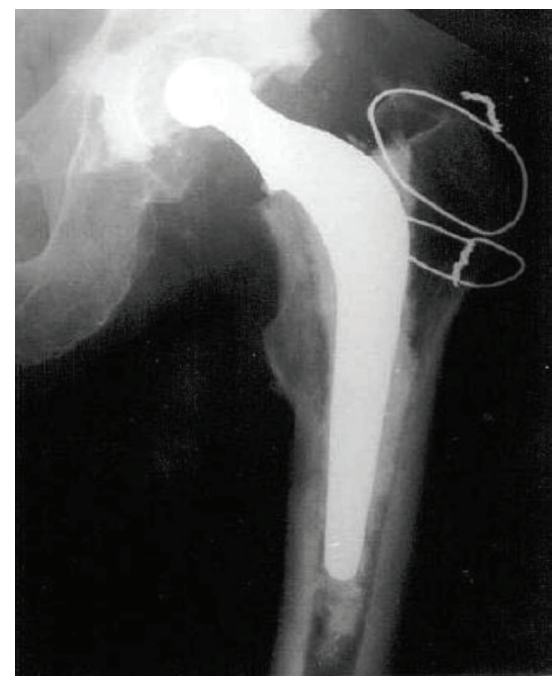

Figure 12: Radiograph of the Total Hip Prosthesis.

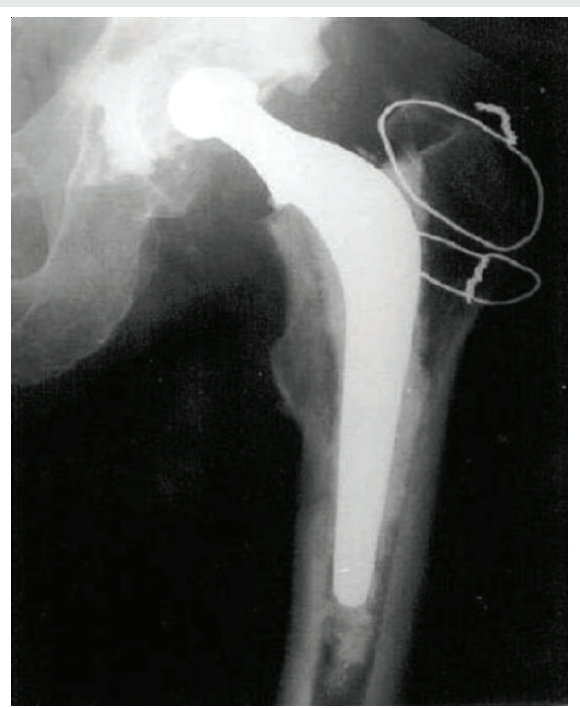

Figure 13: Radiograph of a Thompson's Prosthesis.

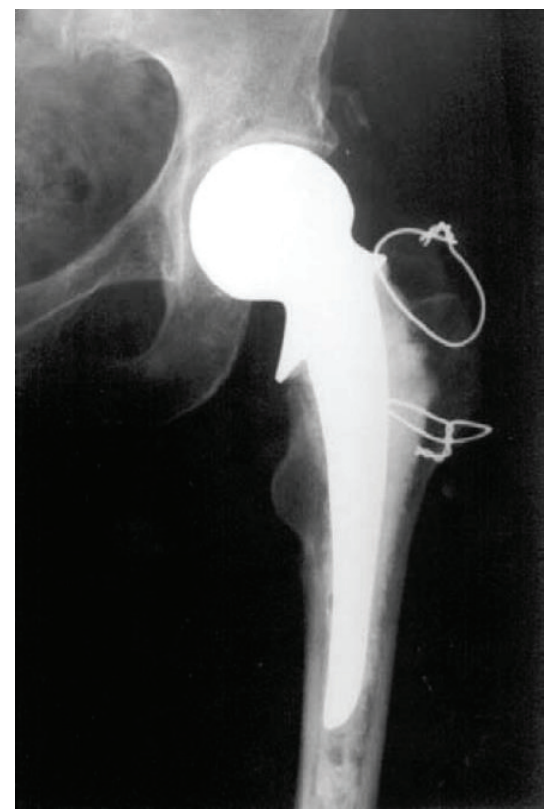

Figure 14: Radiograph of a Bipolar Prosthesis.
So patients will recover pretty soon unlike other approaches where they might take many weeks to recover. Not only physio but also patient and their family members work will reduce drastically if there is no damage to muscles and nerves and less chances of joint dislocation. Moreover, early recovery makes more confidence and daily living activities will improve sooner in those patients who undergo this particular surgery.

Physiotherapy Treatment/ Physical Therapy plays a vital role in patient's recovery. Physiotherapist mainly works on reducing pain and swelling, restoring and maintaining full range of motion, improving muscle strength and endurance, muscle stretching exercises, flexibility, balance exercises, weight bearing activities, promoting independence, other functional activities and many more.

Physiotherapy will continue for a number of weeks after the surgery. This depends on overall situation of the patient and the approach used by Orthopedic Surgeon. If the surgeon uses the modified posterior approach technique, definitely length of the postoperative recovery phase reduces and patient can lead his normal life as soon as possible.

\section{Clinical observations made by the physiotherapist Ritika Sharma bachelors of physiotherapy, Delhi, India}

The posterior approach is the most common surgical approach used internationally for THAs as there are more than 100 described cases in literature. There is no book written on the title (Posterior Approach to the Hip Joint) only but are in chapters in books on the Hip Joint or Approaches to the Hip Joint. This book will be published eventually by CRC Press (Taylor \& Francis,UK) and it has chapterwise contributions from all over the world to include China, Japan, India, UK, USA, Australia, France and Germany which shows the evolution and progress this approach has made since its Start.

1. This modification helps to increase stability of the posterior aspect of the Hip Joint by trochanteric osteotomy of the greater trochanter as noted by its cadaveric tests and hence decreases the risk of dislocation of the Hip Joint.

2. There is minimal bleeding in this approach and no neurological defecit as the sciatic nerve is far away.

3. It does not interfere with the abductor mechanism as it leaves the abductor mechanism intact.

4. There is excellent visualization of all parts of the Hip Joint by this approach and hence useful in Hemiarthroplasty, Total Hip Replacement both primary and revision where there is good visulisation of the femur also.

5. Early postoperative recovery due to early mobilization with reduced length of hospital stay.

Rehabilitation protocols in the Hips operated by the lateral and anterior approaches vary considerably as follows:

Hip positional precautions include no hip adduction past neutral, no hip internal rotation past neutral, and no hip flexion more than 90 degrees for a minimum of 12 weeks until 
soft tissue stabilization can be expected but hip flexion may be increased gradually more than 90 from 6 weeks. An abduction pillow is used for the first 4 weeks while resting or sleeping in bed. For the bathroom an elevated seat is preferred at all times which can be discontinued from the $3^{\text {rd }}$ month onwards. Use of assisted ambulation devices such as cane, walker, quad cane increases the confidence of the patient. Avoid sitting in conventional fashion while driving with the hips flexed more than 90 degrees to avoid posterior dislocation of hip in the event of a sudden stop. Car driving is usually permitted at 6 weeks post-operatively.

In Hips operated by the DAA approach, patient education is very important initially along with instructions on pre-op exercises includes instruction on home safety and pre-surgical lower limb exercises. The immediate postoperative instructions to include safety with mobilization and transfers with icing and elevation, home exercise examples such as ankle pumps, quadriceps exercises hamstring exercises, gluteal exercises, assisted heel slides, hip abduction, external and internal rotation to neutral exercises. The next step being protected motion with muscle activation phase during the next 4 weeks. This will also provide environment for proper healing of the incision site and prevention of postoperative complications. It will also minimize pain and swelling and eventually Improve functional strength and Improve functional hip range of movements which helps in gait.

The DAA can be done on a plain table or a fracture table according to each Surgeons wishes.

The emphasis should be made on quick mobiisation rather than the word dislocation.This can be used extensively in Fracture neck of femur for Hemiarthroplasty [17-19] rather than Primary or Revision Hip Replacement [20].

But with gradual understanding of the DAA, this appears to be a better substitute [21-24]. Rather than these modifications. The DAA may appear to have a very steep and difficult learning curve in the beginning, but with practice and using this DAA, it appears as an excellent substitute for the Posterior Approach to the Hip Joint.

The features of DAA should be shared actively with physio/ occupational therapists to avoid the necessity for the use of a low chair for sitting purposes and avoid cross the legs in bed.

All HOD's in Orthopaedics should impart teaching on DAA to their students at all levels in training so that they are aware of the DAA.

The 'word dislocation' has been looked as a unacceptable/ inadequate/ banned as constituting a risk/ not acceptable to mention associated with mainly Posterior Approach in Surgical Approaches to the Hip Joint since over 5 decades which is extremely difficult to overcome in literature even till today. I had also described a Modified Approach to the Posterior Approach in 1981, which is well held in literature [25] and textbooks (https://kmohaniyer.com) of repute even till today but I feel that we should encourage the younger generations of Orthopaedic Surgeons in the world to embrace the DAA even for the most commonly seen Fracture neck of femur initially instead to straight embarking on Primary or Revision Total Hip Arthroplasty.

I had done a few cases in Hemiarthroplasty only [without using a fracture table] in selective patients which is not ideal and enough to write this chapter which has a difficult learning curve and specialised surgical skills with special instruments including a special operation table for this type of Surgery.

Actually Total Hip Surgery can be done as a day case as seen in my book "Hip Joint in Adults: Advances and Developments" in Chapter no.18 by Dr. med. Manfred Krieger and and Dr. med. Ilan Elias, Wiesbaden, Frankfurt, Germany in 2018. Ideally this is best done by Dr. John O'Donnell, Melbourne Australia with whom I had several interactions saying that he is extremely comfortable with the DAA for his Hip Replacements and that he cannot imagine changing himself for another Surgical Approach that I developed an interest in the DAA. He has also been instrumental in giving me a forward for a small book written by me and published in 2018 by Lambert academic publishing, Germany.

\section{References}

1. Chechik O, Khashan M, Lador R, Salai M, Amar E (2013) Surgical approach and prosthesis fixation in hip arthroplasty worldwide. Arch Orthop Trauma Surg 133: 1595-1600. Link: https://bit.ly/3xscKTT

2. Enocson A, Tidermark J, Törnkvist H, Lapidus LJ (2008) Dislocation of hemiarthroplasty after femoral neck fracture: better outcome after the anterolateral approach in a prospective cohort study on 739 consecutive hips. Acta Orthop 79: 211-217. Link: https://bit.ly/3AgYYFr

3. Masonis J, Thompson C, Odum S (2008) Safe and accurate: learning the direct anterior total hip arthroplasty. Orthopedics 31. Link: https://bit.ly/3rXnCba

4. Jolles BM, Bogoch ER (2006) Posterior versus lateral surgical approach for total hip arthroplasty in adults with osteoarthritis. Cochrane Database Syst Rev 3. Link: https://bit.ly/3AhML3q

5. Coventry MB (1982) The Year Book of Orthopaedics 371-373. Link https://bit.ly/3AdN3lo

6. Canale ST (1992) Campbell's Operative Orthopaedics. Ninth Edition. 1: 140

7. Beddow FH, Tulloch C, Bone J (1990) Rheumatoid Arthritis Surgical SocietyClinical Experience with the lyer modification of the Posterior Approach to the Hip. Joint Surg 73: 164-165.

8. Shaw JA (1991) Experience with modified Posterior Approach to the Hip Joint. A Technical note: J Arthroplasty 6: 11-18. Link: https://bit.ly/3jsvQ7i

9. Callaghan JJ, Rosenberg AG, Rubash HE, Clohisy JC, Beaulé PE, et al. (1998) The Adult Hip (Lippincott Raven). 1: 700-718.

10. Fractures of the Hip in Adults: by Raymond G Tronzo. 333

11. Hozak WJ, Kirsmer M, Hogler M, Bonutti PM, Rachbauer F, et al. (2004) Minimally unvasive Total Joint Arthroplasty. Link: https://bit.ly/3fPttKD

12. Stähelin T, Vienne P, Hersche $O$ (2002) Failure of Reinserted Short Externa Rotator Muscles after Total Hip Arthroplasty. J Arthroplasty 17: 604-607. Link: https://bit.ly/3yxipt5

13. Iyer D (2006) The Orthopaedic Enigma: A Simplified Classification. Internet Journal of Orthopaedic Surgery 3. Link: https://bit.ly/2VtuReN 


\section{Robert CH (2010) Personal Communication.}

15. Sanchez-Sotelo J, Gipple J, Berry D, Rowland C, Cofield R (2005) Primary hip arthroplasty through a limited posterior trochnteric osteotomy. Acta Orthop Belg 71: 548-554. Link: https://bit.ly/3io5Z14

16. Iyer MK (2021) The Hip Joint (2 ${ }^{\text {nd }}$ Edition) Jenny Stanford Publishing (Singapore). Link: https://bit.ly/3ysxnAw

17. Iyer MK (2017) Int J Surg \& Trans Res1: 59-52.

18. (2017) Heutor's Anterior Approach to the Hip Joint. EC Orthopaedics 9: 03-06.

19. The Direct Anterior Approach to the Hip Joint.Ortho Res Online J.3(3) OPROJ 000565.2018 [Crimson Publishers (Orthopaedic Research Online Journal) [ISSN: 2576-8875].

20. Mohan IK (2018) Direct Anterior Approach to the Hip Joint. Int J Sur Trans Res 1: 49-52. Link: https://bit.ly/3fDbrLM
21. "Hip Joint in Adults: Advances and Developments": Direct Anterior Approach to the Hip Joint, by John O'Donnell, Melbourne Australia.

22. Hip Joint in Adults: Advances and Developments. Total hip in a day, setup and early experiences in outpatient hip surgery, by Dr. med. Manfred Krieger and Dr. med. Ilan Elias, Wiesbaden, Frankfurt, Germany. Link: https://bit.ly/37nRP9N

23. Hip Preservation Techniques. The anterior approach to the hip for a minimally invasive prosthesis by Alessandro Geraci, MD, PhD; Alberto Ricciardi, MD Orthopaedic Department, San Giacomo Apostolo Hospital, Castelfranco Veneto, Italy.

24. General Principles of Orthopaedics and Truama ( $2^{\text {nd }}$ edition by K.Mohan lyer \& Wasim Khan), The Direct Anterior approach to the Hip by Hiran Amarasekera. Link: https://bit.ly/3rVvLNa

25. Link: https://kmohaniyer.com/

\section{Discover a bigger Impact and Visibility of your article publication with}

\section{Peertechz Publications}

\section{Highlights}

* Signatory publisher of ORCID

* Signatory Publisher of DORA (San Francisco Declaration on Research Assessment)

* Articles archived in worlds' renowned service providers such as Portico, CNKI, AGRIS, TDNet, Base (Bielefeld University Library), CrossRef, Scilit, J-Gate etc.

- Journals indexed in ICMJE, SHERPA/ROMEO, Google Scholar etc.

- OAI-PMH (Open Archives Initiative Protocol for Metadata Harvesting)

* Dedicated Editorial Board for every journa

* Accurate and rapid peer-review process

* Increased citations of published articles through promotions

* Reduced timeline for article publication

Submit your articles and experience a new surge in publication services (https://www.peertechz.com/submission).

Peertechz journals wishes everlasting success in your every endeavours.

Copyright: @ 2021 lyer KM. This is an open-access article distributed under the terms of the Creative Commons Attribution License, which permits unrestricted use, distribution, and reproduction in any medium, provided the original author and source are credited. 